\title{
EFFECT OF DIFFERENT TYPES OF RICE HUSK ASH ON SOME GEOTECHNICAL PROPERTIES OF CEMENT-ADMIXED SOIL
}

\author{
${ }^{1}$ Nguyen Thanh Duong* and ${ }^{1}$ Nguyen Thi Nu \\ ${ }^{1}$ Hanoi University of Mining and Geology, Hanoi, Vietnam \\ *E-mail: nguyenthanhduong@ humg.edu.vn \\ Received: 11 May 2020; accepted: 9 July 2020
}

\begin{abstract}
Rice husk ash (RHA) is an agricultural residue and has shown great potential for soil stabilization. However, the research on the utilization of RHA for soft soil improvement using cement deep mixing method is still limited and the efficiency of using different RHA types for soil improvement needs to be clarified. In this study, the effect of different RHA types on Atterberg limits, unconfined compressive strength (UCS), and elastic modulus ( $\left.E_{50}\right)$ of soilcement mixtures will be investigated. Two types of RHA which obtained from open fire burning (RHA1) and burning in a furnace under controlled conditions of temperature and duration of burning (RHA2), were used for this study. The RHA contents from 0 to $15 \%$ and $10 \%$ cement of the dry weight of the soil were used to treat the soft soil. The research results show that the types of RHA insignificantly affect the change in Atterberg limits of cement-admixed soil. Regarding the soil strength, the RHA2 shows a higher efficiency in the enhancement of treated soil strength at 28 days of curing than the RHA1. The addition of 12\% RHA2 to the cement-admixed soil can increase the UCS and $E_{50}$ values of treated soil by more than $50 \%$.
\end{abstract}

Keywords: RHA; Open fire burning; Atterberg limits; UCS; E50; Cement-admixed soil

\section{INTRODUCTION}

Recently, the use of industrial and agricultural wastes such as fly ash, steel slag, blast furnace slag, rice husk ash (RHA), wood ash, and bagasse ash in civil engineering applications is one of the great interests and has received much attention from the literature (e.g., James and Pandian, 2016; Jayanthi and Singh, 2016; Kuntikana and Singh, 2017 and Varaprasad et al., 2020). The utilization of these wastes could reduce the amount of landfilled, replace natural aggregates such as sand, gravel or even conventional Portland cement as well as reduce the construction cost. However, the utilization of RHA as a pozzolanic material in civil engineering is still limited. Rice husk ash 
(RHA) is an agricultural-by product that is abundant in many developing countries such as China, India, the USA, Brazil, and Southeast Asia (Hossain et al., 2018). The ash is porous, lightweight, and contains a high content of silica with above $70 \%$, even up to $98 \%$ (Fapohunda et al., 2017). However, the RHA is often treated as waste and disposed of to the environment and may cause a serious problem for the air and water environments, and human health. Thus, it is necessary to increase the utilization of this waste in civil engineering application to reduce the negative effect on the environment and reduce the construction cost as well.

One of the civil engineering applications that can utilize the RHA is soil improvement. The silica in RHA can be reacted with calcium hydroxide in lime and cement to form the cementitious products which can enhance the soil strength. Thi Nu et al. 2020 mentioned that the increase in salt and alum contents caused a decrease in undrained shear strength and an increase in liquid limit and compression index. Thus, the salt content in soil can impact many fields (Al-Hamdani et al., 2016). Many investigations have been conducted to examine the suitability of soil stabilization with RHA and cement ( Hossain, 2011; Basha et al., 2005; Jongpradist et al., 2018; Rahman, 1987; Roy, 2014; Yoobanpot and Jamsawang, 2014). However, most of these investigations examined the utilization of RHA to stabilize soils for base and sub-base layers in pavement and road applications. Recently, Jongpradist et al. (2018) have investigated the use of RHA as a cementitious material in high-strength cement-admixed clay in the cement deep mixing method. In their research, the RHA and cement contents used ranged from 5 to $35 \%$ and 10 to $30 \%$ respectively. The research results found that the RHA significantly improved the strength of soil-cement admixtures with the cement content above 20\%. However, according to Farouk and Shahien (2013), from the literature, the amount of cement used in the soil-cement column is typically ranged from 5 to $16 \%$ of the weight of the soil (Farouk and Shahien, 2013). Therefore, the use of RHA in combination with cement content in the typical range for cement deep mixing method should be extensively examined. Furthermore, the quality of RHA that is the content of amorphous silica in RHA significantly depends on the burning condition (temperature and duration of burning). The amount of amorphous silica will affect the pozzolanic reaction and the formation of gel CSH (Behak, 2017). However, the effect of different types of RHA on the efficiency of soil improvement is rarely examined. In Vietnam, burning rice residue, including rice husk, in open fire is very common, especially in rural areas (Lasko and Vadrevu, 2018 and Thao et al., 2011). Thus, the use of RHA from this condition for soil improvement should be investigated. In this study, the effect 
of two types of RHA, including the RHA obtained from open fire burning and the RHA obtained from burning in controlled conditions of temperature and duration, on some geotechnical properties of cement-admixed soil will be investigated. The amount of RHA of 5, 8, 12, and $15 \%$ and cement content of $10 \%$ of the dry weight of the soil to be treated were used for this investigation. The Atterberg limits of soil-cement-RHA admixtures were determined; the unconfined compressive strength and elastic modulus ( $\left.\mathrm{E}_{50}\right)$ of admixtures were determined at 28 days of curing.

\section{MATERIALS AND METHODS}

\section{Burning Rice Husk and Properties of Rice Husk Ash}

The temperature and duration of burning rice husk significantly affect the quality of RHA. Behak (2017) found that the RHA from burning rice husk in a controlled temperature of $650^{\circ} \mathrm{C}-800^{\circ} \mathrm{C}$ (in incinerator) was more reactive than that from burning in uncontrolled temperature (in conventional ovens). Cordeiro et al. (2009) revealed that the RHA obtained from uncontrolled burning conditions often contained high carbon content with low pozzolanic activity. Nguyen et al. (2011) also stated that the RHA with high reactive silica content cannot be obtained from open burning of rice husk and burning rice husk below the temperature of $500^{\circ} \mathrm{C}$. Under uncontrolled conditions, the RHA from bio-mass power plants and open burning were not fully burned and contained a high carbon content and high loss of ignition (LOI) (Karatai et al., 2016 and Liu et al., 2019b, 2019a). Therefore, burning rice husk in controlled conditions of temperature and time is often used to produce RHA with high pozzolanic activity.

However, burning rice husk in the open fire under uncontrolled conditions of burning temperature and time is popular in Vietnam, especially in rural areas. In this study, the rice husk ash from open fire burning (RHA1) and from controlled burning conditions (RHA2) were collected. In open fire, the rice husk was burned for about 5-6 hours to obtain RHA1. The RHA2 was obtained from burning rice husk in a furnace at a temperature of $600^{\circ} \mathrm{C}$ and 2 hours of burning. The RHA after collecting was ground and passed through the sieve of No. $40(425 \mu \mathrm{m})$. The physical properties and chemical compositions of two types of RHA are shown in Table 1. The RHA1 contains a lower content of silica, a higher content of LOI compared to the RHA2. Regarding the color, the color of RHA2 is lighter than that of RHA1 (Fig. 1). This result is consistent with the statement of Houston (1972). Accordingly, the lighter color of RHA2 is a result of a higher content of silica. 

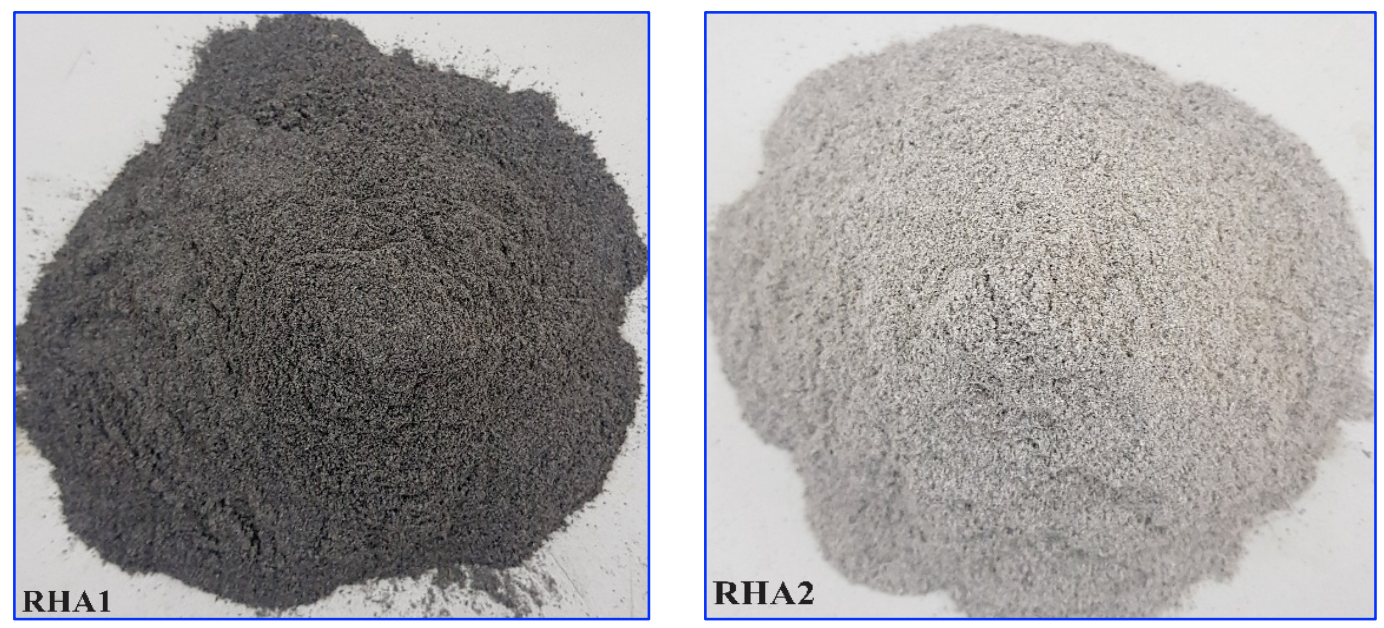

Fig. 1. The color of ground RHA used in this study

Table 1. Physical properties and chemical compositions of RHA used in this study

\begin{tabular}{|c|c|c|c|}
\hline \multicolumn{2}{|c|}{ Properties } & $\begin{array}{c}\text { RHA1 (high carbon } \\
\text { content) }\end{array}$ & $\begin{array}{c}\text { RHA2 (low carbon } \\
\text { content) }\end{array}$ \\
\hline \multicolumn{2}{|c|}{ Specific gravity } & 1.94 & 2.24 \\
\hline Physical properties & Color & Blackish grey & Whitish grey \\
\hline \multirow{15}{*}{$\begin{array}{c}\text { Chemical } \\
\text { compositions (\%) }\end{array}$} & $\mathrm{SiO}_{2}$ & 58.61 & 77.56 \\
\hline & $\mathrm{Fe}_{2} \mathrm{O}_{3}$ & 0.17 & 0.40 \\
\hline & $\mathrm{Al}_{2} \mathrm{O}_{3}$ & 0.20 & 0.48 \\
\hline & $\mathrm{TiO}_{2}$ & 0.03 & 0.04 \\
\hline & $\mathrm{MnO}$ & 0.18 & 0.23 \\
\hline & $\mathrm{Na}_{2} \mathrm{O}$ & 0.03 & 0.07 \\
\hline & $\mathrm{K}_{2} \mathrm{O}$ & 3.35 & 5.34 \\
\hline & $\mathrm{CaO}$ & 1.25 & 2.25 \\
\hline & $\mathrm{MgO}$ & 0.71 & 1.21 \\
\hline & $\mathrm{P}_{2} \mathrm{O}_{5}$ & 0.63 & 1.02 \\
\hline & $\mathrm{SO}_{3}$ & 1.03 & 3.04 \\
\hline & $\mathrm{Cr}_{2} \mathrm{O}_{3}$ & $<0.01$ & $<0.01$ \\
\hline & $\mathrm{Cl}$ & 0.33 & 0.29 \\
\hline & LOI (Loss of Ignition) & 33.25 & 8.08 \\
\hline & $\mathrm{SiO}_{2}+\mathrm{Fe}_{2} \mathrm{O}_{3}+\mathrm{Al}_{2} \mathrm{O}_{3}$ & 58.98 & 78.44 \\
\hline
\end{tabular}

\section{Soil and Cement}

The soil sample was collected from the borehole at the depth of 1-2 $\mathrm{m}$ in Thanh Hoa province, Vietnam. The size of soil particles is shown in Fig. 2. Some physio-mechanical properties of 
studied soil are presented in Table 2. The studied soil is blackish grey, brownish grey clay with the soft state and the content of organic matter in the soil is rather high with $9.8 \%$. The strength of the soil sample is very low with the unconfined compressive strength (UCS) value of $14.7 \mathrm{kPa}$. In this study, the Portland cement PCB40 from VICEM (Vietnam National Cement Corporation) was used. This cement contains $63.5 \% \mathrm{CaO}, 20.22 \% \mathrm{SiO}_{2}$, and $16.28 \%$ for other compositions such as $\mathrm{Fe}_{2} \mathrm{O}_{3}, \mathrm{Al}_{2} \mathrm{O}_{3}, \mathrm{SO}_{3}$.

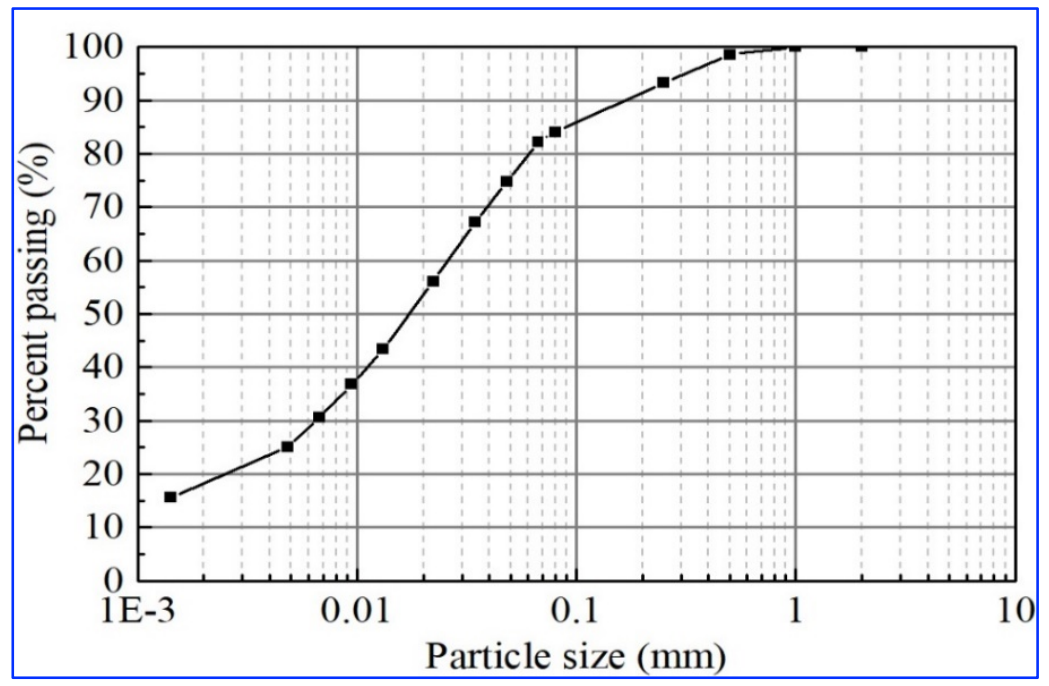

Fig. 2. Particle size distribution of soil sample used

Table 2. Properties of soil sample

\begin{tabular}{|l|c|c|}
\hline Index property & Unit & Index value \\
\hline Natural water content & $\%$ & 88.0 \\
\hline Unit weight & $\mathrm{g} / \mathrm{cm}^{3}$ & 1.67 \\
\hline Dry unit weight & $\mathrm{g} / \mathrm{cm}^{3}$ & 0.89 \\
\hline Void ratio & - & 2.026 \\
\hline Specific gravity & - & 2.68 \\
\hline Liquid limit & $\%$ & 91.9 \\
\hline Plasticity limit & $\%$ & 48.4 \\
\hline Plasticity index & - & 43.5 \\
\hline Liquidity index & - & 0.91 \\
\hline Organic matter & $\%$ & 9.8 \\
\hline Unconfined compressive strength (UCS) & $\mathrm{kPa}$ & 14.7 \\
\hline
\end{tabular}

\section{Sample Preparation and Method}

The Atterberg limits of soil-cement-RHA admixtures were determined at 0 day of curing ( 0 day after mixing) following ASTM D4318-00. 
For UCS tests, the soil-cement-RHA admixtures were prepared in the metal cylindrical mold with a height of $10 \mathrm{~cm}$, a diameter of $5 \mathrm{~cm}$. This size of the sample for determination of UCS values was also used in the previous studies (Horpibulsuk et al., 2011, 2005; Chew et al., 2004; Miura et al., 2001; Yoobanpot and Jamsawang, 2014). The admixtures in the form of slurry were created by mixing soil with $10 \%$ cement and different RHA contents of 5, 8, 12, and $15 \%$ in a mixer for about 5 to 10 minutes. The admixture of soil with $10 \%$ cement and $0 \%$ RHA was also prepared for a controlled sample. In all admixtures, the ratio of water to cement is 1 . The slurry of admixtures was then placed and compacted into the metal mold in three layers. The surface of the sample was flattened, and the sample was then weighted. After three days of molding, the specimens were removed from the mold and were then sealed using a plastic box to maintain the moisture content. All the specimens were cured at room humidity and temperature for 28 days before testing. The UCS values of soil-cement-RHA admixtures were determined in accordance with ASTM D216600 with the loading rate of $1 \mathrm{~mm} / \mathrm{min}$. The elastic modulus $\left(E_{50}\right)$ that was the secant modulus at $50 \%$ of compressive strength was also calculated.

\section{TEST RESULTS AND DISCUSSIONS}

\section{Atterberg Limit}

The results of the liquid limit (LL), plasticity limit (PL), and plasticity index (PI) of soil-cementRHA admixtures are shown in Fig. 3. For both types of RHA, the LL and PL values slightly increase as the RHA content increases. However, the increase of PL is more pronounced than that of LL. The tendency of LL and PL after adding RHA to soil-cement mixtures observed in this study is similar to that after adding cement or RHA to soil observed in previous studies (Basha et al., 2005). The increase of LL can be attributed to the more water needed for the soil fluid when the RHA is added (Okafor and Okonkwo, 2009 and Sarkar et al., 2012). The increase of PL can be due to the pozzolanic characteristics of RHA (Fattah et al., 2013 and Sarkar et al., 2012). The plasticity index of soil treated with cement and RHA shows a general decrease trend. In which, the PI of soil treated with cement and RHA1 decreases from 41.2 to $35.3 \%$, while that of soil treated with cement and RHA2 decreases from 41.2 to $35.5 \%$. This indicates that the types of RHA insignificantly affect the change in the plasticity index of soil treated with cement and RHA. 

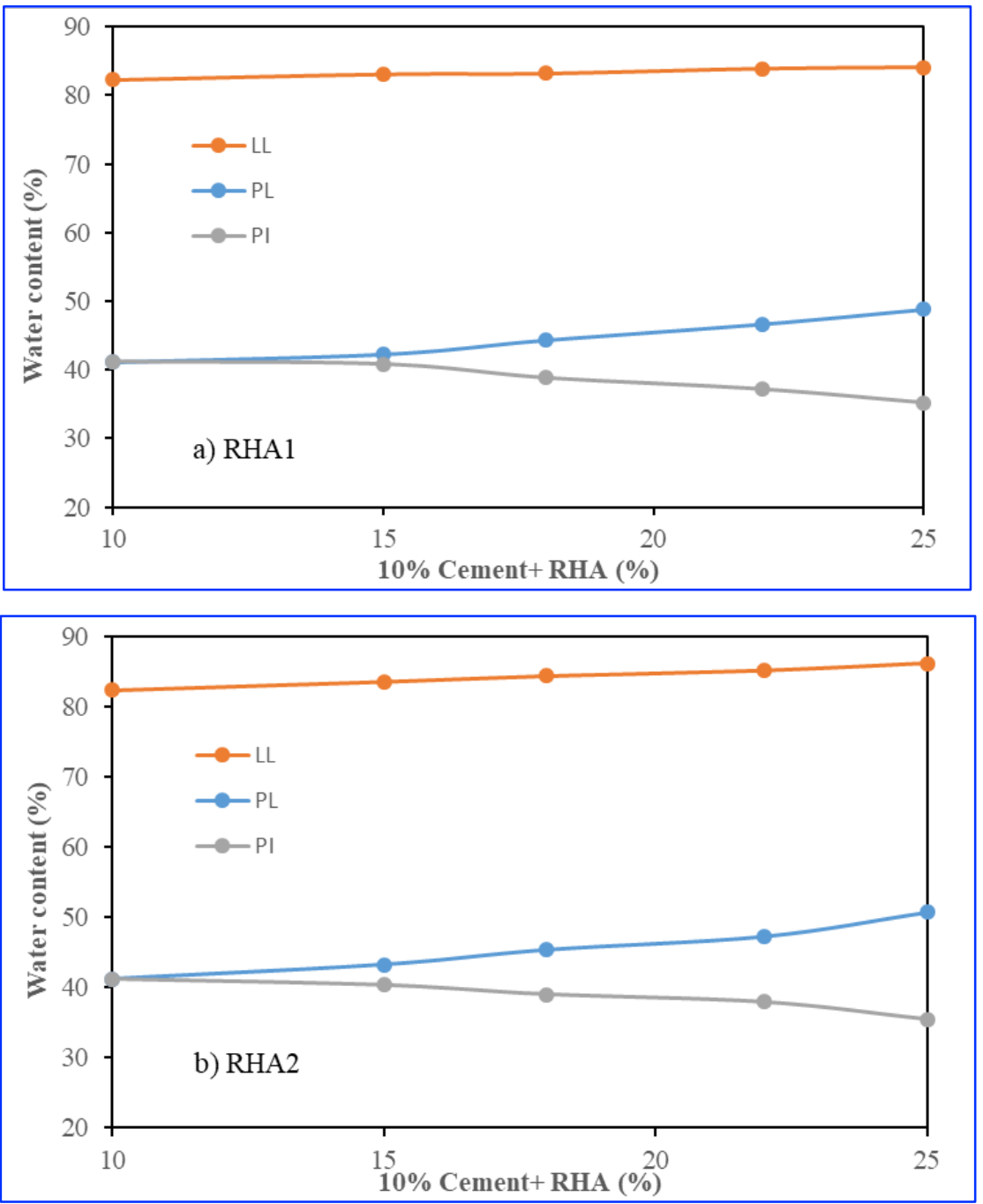

Fig. 3. Variation of Atterberg limits of soil-cement-RHA admixtures

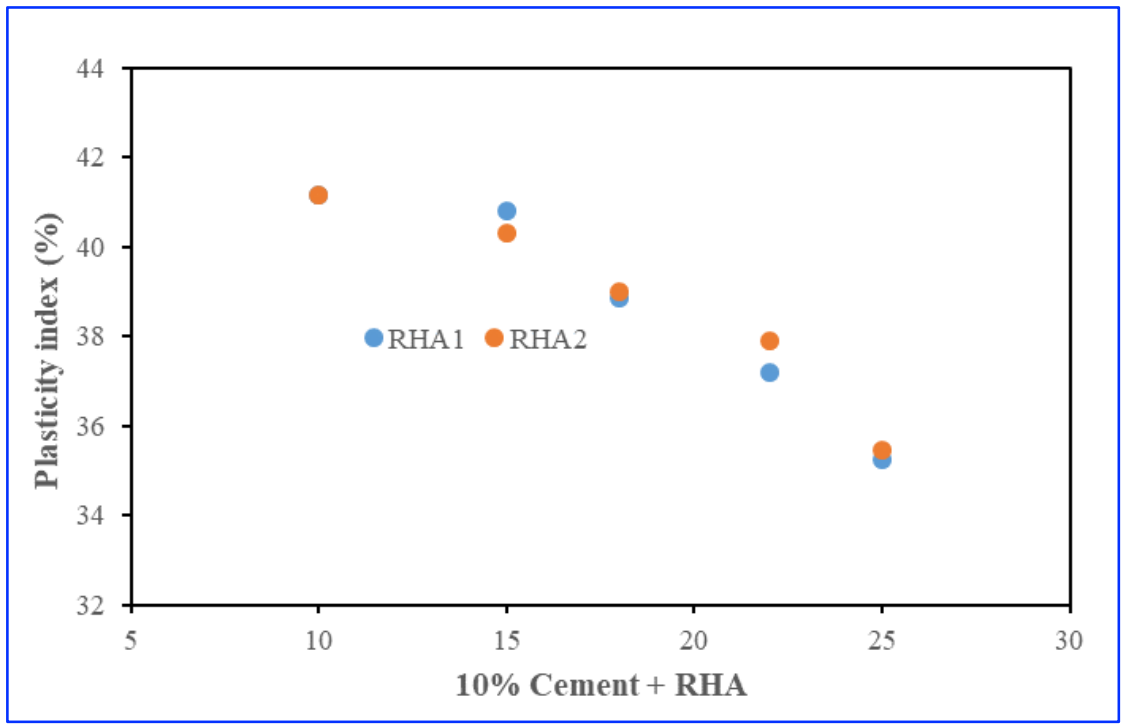

Fig. 4. Effect of RHA on the PI of treated soil with cement and RHA 


\section{Unconfined Compressive Strength and Elastic Modulus}

The results of UCS from the unconfined compression test and calculated elastic modulus ( $\left.\mathrm{E}_{50}\right)$ are shown in Table 3. The variation of UCS of soil treated with cement and different RHA contents is shown in Fig. 5. The increase in the content of RHA1 leads to a slight increase in the UCS values. However, the increase in the content of RHA2 leads to a significant increase in UCS values. The highest UCS of soil treated with 10\% cement and different types of RHA was observed at $8 \%$ RHA1 and 12\% RHA2 (Fig. 5).

Nevertheless, the addition of $8 \%$ RHA1 to the soil-cement mixture increases only about $6 \%$ of UCS values while the addition of $12 \%$ RHA 2 can lead to more than $50 \%$ increase in UCS values. This increases that the pozzolanic activity of RHA2 is significantly higher than that of RHA1. This is attributed to the difference in burning conditions. In other words, the RHA obtained from controlled burning can result in a higher soil strength enhancement compared to the RHA obtained from uncontrolled burning. For both types of RHA, the RHA increasing above the optimum content will result in a decrease of UCS.

This tendency is also observed in previous studies. Yoobanpot and Jamsawang (2014) showed that the highest UCS of soil-cement admixture was found at 30\% RHA replacement cement in the cement deep mixing method. In general, the decrease of UCS can be attributed to the lack of water for the pozzolanic reaction when the RHA increases above the optimum content. In addition, since the RHA is a non-plastic material, the redundant RHA can lead to decrease the soil strength. These causes are similar to the use of granulated blast furnace slag (GBFS) and ground granulated blast furnace slag (GGBFS) for the soil improvement (Sekhar et al., 2017 and Sharma and Sivapullaiah, 2016).

Regarding the effect of RHA types on UCS, as shown in Fig. 5, the UCS values of soil treated with cement and RHA1 is significantly lower than those of soil treated with cement and RHA2. This is attributed to the low silica content and the high carbon content of RHA1. Previous studies showed that the pozzolanic activity of RHA plays an important role in the enhancement of soil strength (Behak, 2017; Boateng and Skeete, 1990). Thus, the low silica content will lower the soil strength enhancement. Besides, the high carbon content in RHA can hidden the pozzolanic reaction and results in a lower increase in soil strength. 
Table 3. Results of UCS and $E_{50}$ of soil treated with cement and RHA

\begin{tabular}{|c|c|c|c|c|c|}
\hline \multirow{2}{*}{$\begin{array}{c}\text { RHA } \\
\text { content }(\%)\end{array}$} & $\begin{array}{c}\text { Cement content } \\
(\%)\end{array}$ & \multicolumn{2}{|c|}{ UCS (kPa) } & \multicolumn{2}{c|}{ E50 (kPa) } \\
\cline { 3 - 6 } & $\mathbf{\text { \%HA1 }}$ & RHA2 & RHA1 & RHA2 \\
\hline 0 & 10 & 106.2 & 106.2 & 7662 & 7662 \\
\hline 5 & 10 & 92.8 & 114.2 & 6199 & 7748 \\
\hline 8 & 10 & 113 & 155.6 & 6551 & 9169 \\
\hline 12 & 10 & 60.5 & 170.5 & 3952 & 11397 \\
\hline 15 & 10 & 79.4 & 135.9 & 4411 & 8138 \\
\hline
\end{tabular}

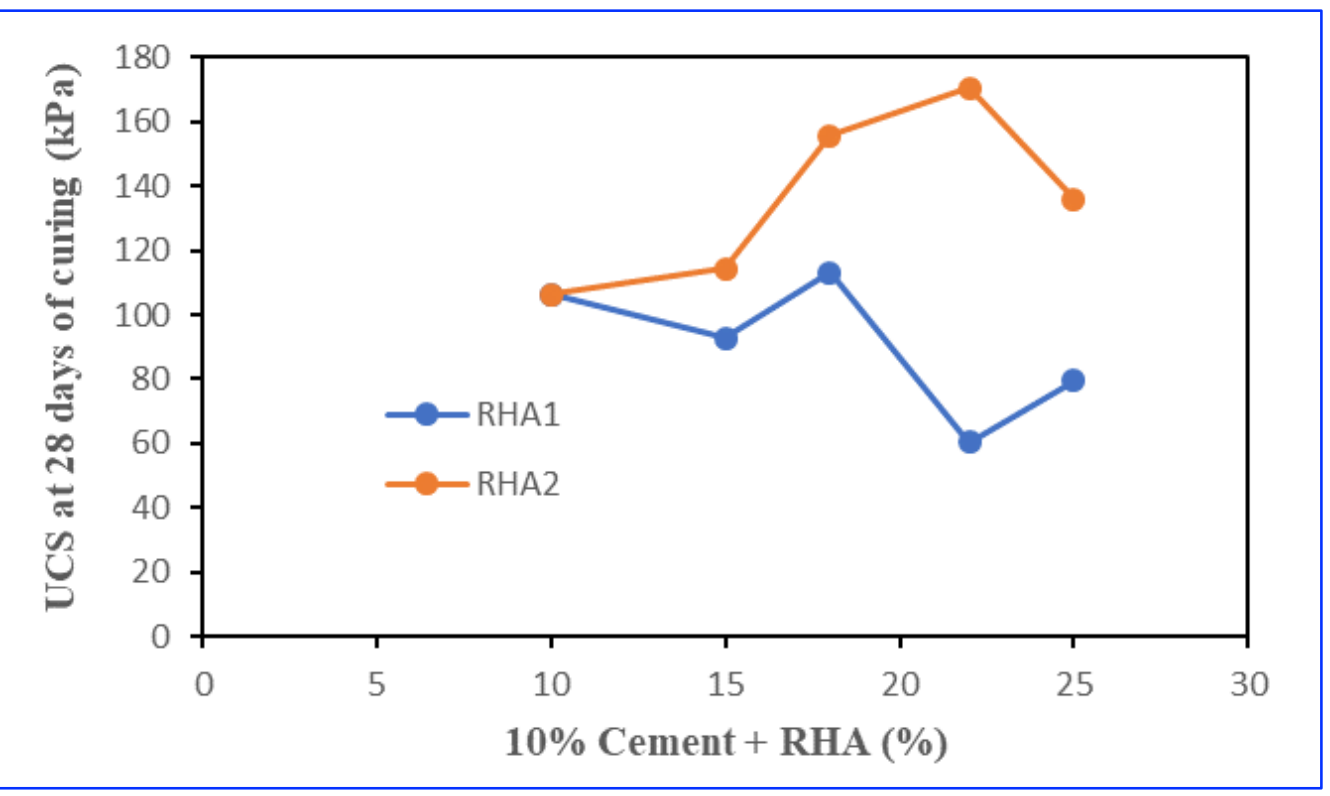

Fig. 5. Variation of UCS values of soil treated with cement and RHA

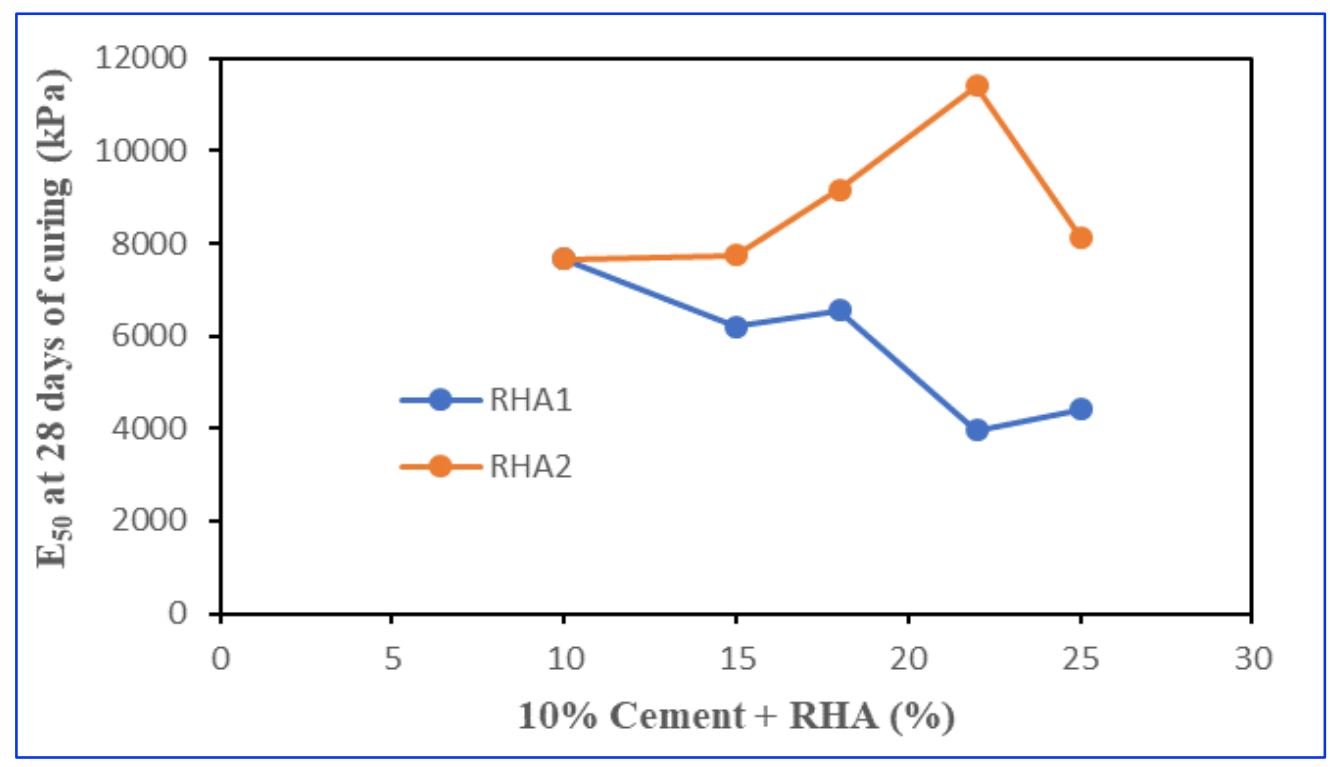

Fig. 6. Variation of $E_{50}$ values of soil treated with cement and RHA 
The variation of UCS of soil is treated with cement and different RHA contents (Fig. 6). Like the UCS values, the increase of RHA2 content leads to a significant increase in the elastic modulus $\left(\mathrm{E}_{50}\right)$ of treated soil. The highest value of $\mathrm{E}_{50}$ is also found when 12\% RHA content is added to cement-admixed soil. Accordingly, the addition of $12 \%$ RHA2 can increase the $\mathrm{E}_{50}$ value of treated soil by 55\%. By contrast, the increase of RHA1 content results in a decrease in the $\mathrm{E}_{50}$ of treated soil. This indicates that the RHA2 is more effective than the RHA1 in soil improvement for both UCS and $\mathrm{E}_{50}$ parameters. As mentioned above, the reason here is attributed to higher pozzolanic reaction activity of RHA2 compared to that of RHA1.

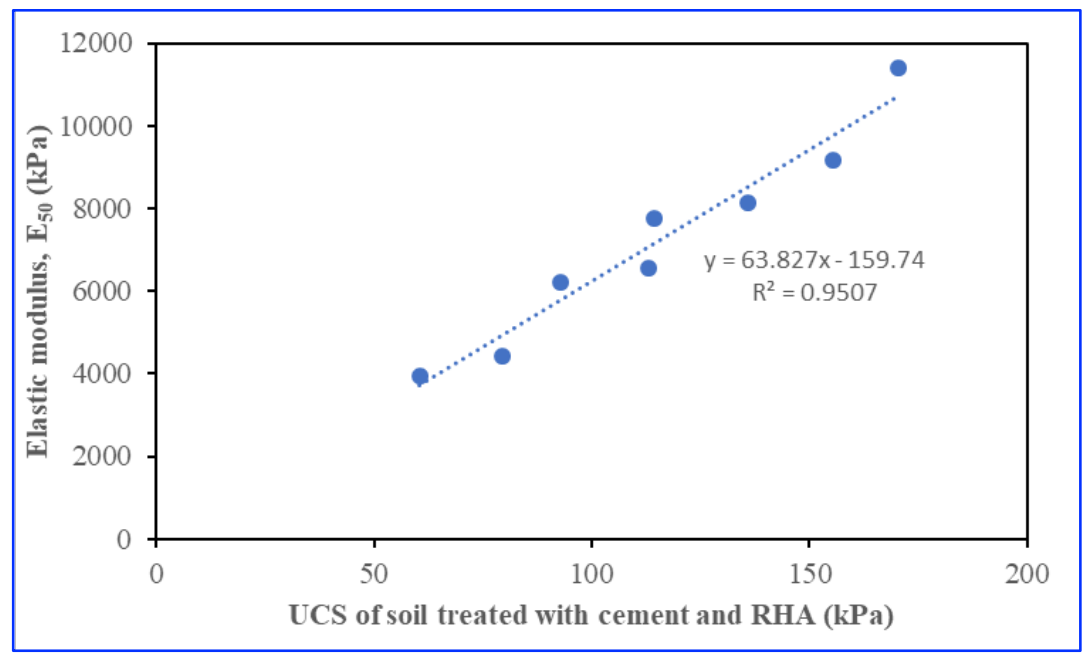

Fig. 7. Relationship between UCS and $E_{50}$ for soil treated with cement and RHA

The relationship between UCS and $\mathrm{E}_{50}$ parameters for soil treated with cement and different types of RHA is plotted in Fig. 7. The $\mathrm{E}_{50}$ of soil is treated with cement and RHA at 28 days of curing can be estimated as $63.8 \mathrm{UCS}$ (coefficient of determination, $\mathrm{R}^{2}=0.95$ ). This result is almost similar to that of Yoobanpot and Jamsawang (2014) while it is slightly lower than that of Jongpradist et al. (2018). Accordingly, the $\mathrm{E}_{50}$ of soil treated with cement and RHA can be equal to 61.2UCS $\left(\mathrm{R}^{2}=0.98\right)$ (Yoobanpot and Jamsawang, 2014) and 84.3UCS $\left(\mathrm{R}^{2}=0.91\right)$ (Jongpradist et al., 2018). For deep mixing using only cement, the $\mathrm{E}_{50}$ can be equal to $30 \mathrm{UCS} \div 300 \mathrm{UCS}$ (Fang et al., 2001) or 350UCS $\div 1000$ UCS (Kawasaki et al., 1981). The JSG Association of Japan (1986) proposed the relationship $\mathrm{E}_{50}=100 \mathrm{UCS} \div 300 \mathrm{UCS}$ for the jet grouting method.

\section{CONCLUSIONS}

Based on the results of this experimental investigation, the effect of RHA types on some geotechnical properties of cement-admixed soil has been clarified. Accordingly, for both types of studied RHA, the increase in RHA content leads to a reduction in the plasticity index of soil-cement 
mixtures. However, the types of RHA do not affect the decrease of this index. By contrast, the soil strength of treated soil significantly depends on the types of RHA. In which, the RHA obtained from controlled burning in a furnace (RHA2) results in a significant increase of both UCS and $\mathrm{E}_{50}$ values of cement-admixed soil at 28 days of curing, especially with the addition of $12 \%$ RHA2, while the RHA obtained from the open fire burning (RHA1) has a little effect on the enhancement of treated soil strength. The addition of $12 \%$ RHA2 can increase the UCS and $\mathrm{E}_{50}$ of treated soil by more than 50\% compared to those of cement-admixed soil without RHA.

\section{ACKNOWLEDGMENTS}

This research was supported by Hanoi University of Mining and Geology (HUMG) under project number T19-35. I would like to thank my colleagues at the Department of Engineering Geology, HUMG. The authors are very grateful to the Editor in Chief Prof. Dr. Salih M. Awadh, the Secretary of Journal Mr. Samir R. Hijab and the Technical Editor Dr. Heba S. Al-Mimar for their great efforts and valuable comments.

\section{REFERENCES}

Al-Hamdani, J. A. J, Awadh, S. M., and Ibrahim, O. S., 2016. Geochemical partitioning of heavy metals in Urban soil, Kirkuk, Iraq. Iraqi Geological Journal., 39-49.

ASTM D2166 - 00. Standard test method for unconfined compressive strength of cohesive soil.

ASTM D4318 - 00. Standard test methods for liquid limit, plastic limit, and plasticity index of soils

Basha, E. A., Hashim, R., Mahmud, H. B., Muntohar, A. S., 2005. Stabilization of residual soil with rice husk ash and cement. Construction and building materials, 19: 448-453.

Behak, L., 2017. Soil Stabilization with Rice Husk Ash. Chapter 3 in Rice-Technology and Production.

Chew, S. H., Kamruzzaman, A. H. M., Lee, F. H., 2004. Physicochemical and engineering behavior of cement treated clays. Journal of geotechnical and geoenvironmental engineering, 130: 696-706.

Cordeiro, G. C., Toledo Filho, R. D., Fairbairn, E. de M.R., 2009. Use of ultrafine rice husk ash with high-carbon content as pozzolan in high performance concrete. Materials and structures, 42: 983-992.

Fapohunda, C., Akinbile, B., Shittu, A., 2017. Structure and properties of mortar and concrete with rice husk ash as partial replacement of ordinary Portland cement-A review. International Journal of Sustainable Built Environment, 6: 675-692.

Farouk, A., Shahien, M. M., 2013. Ground improvement using soil-cement columns: Experimental investigation. Alexandria Engineering Journal, 52: 733-740.

Fang, Y. S., Chungy, Y. T., Yu, F. J., and Chen, T. J., 2001. Properties of soil-cement stabilised with deep mixing method, Ground Improvement (2001) 5 (2): 69-74.

Fattah, M. Y., Rahil, F. H., Al-Soudany, K. Y., 2013. Improvement of clayey soil characteristics using rice husk ash. Journal of Civil Engineering and Urbanism, 3:12-18.

Hossain, K. M. A, 2011. Stabilized soils incorporating combinations of rice husk ash and cement kiln dust. Journal of Materials in Civil Engineering, 23: 1320-1327.

Hossain, S. S., Mathur, L., Roy, P. K., 2018. Rice husk/rice husk ash as an alternative source of silica in ceramics: A review. Journal of Asian Ceramic Societies, 6: 299-313.

Horpibulsuk, S., Miura, N., Nagaraj, T. S., 2005. Clay-water/ cement ratio identity for cement admixed soft clays. Journal of Geotechnical and Geoenvironmental Engineering, 131:187-192. 
Horpibulsuk, S., Rachan, R., Suddeepong, A., 2011. Assessment of strength development in blended cement admixed Bangkok clay. Construction and Building Materials, 25:1521-1531.

James, J., Pandian, P. K., 2016. Industrial wastes as auxiliary additives to cement/lime stabilization of soils. Advances in Civil Engineering 2016.

Jayanthi, P. N., Singh, D. N., 2016. Utilization of sustainable materials for soil stabilization: state-of-the-art. Advances in Civil Engineering Materials, 5: 46-79.

Jongpradist, P., Homtragoon, W., Sukkarak, R., Kongkitkul, W., Jamsawang, P., 2018. Efficiency of rice husk ash as cementitious material in high-strength cement-admixed clay. Advances in Civil Engineering 2018.

JSG Association., 1986. JSG method-technical information, Tokyo, Japan, 89 pp (in Japanese)

Karatai, T. R., Kaluli, J. W., Kabubo, C., Thiong'o, G., 2016. Soil stabilization using rice husk ash and natural lime as an alternative to cutting and filling in road construction. Journal of Construction Engineering and Management.

Kawasaki, T., Nina, A., Saitoh, S., Suzuki, Y., Honzo, Y., 1981. Deep mixing method using cement hardening agent. Proceedings of the $10^{\text {th }}$ International conference on soil mechanics and foundation engineering, Stockholm.

Kuntikana, G., Singh, D.N., 2017. Contemporary issues related to utilization of industrial byproducts. Advances in Civil Engineering Materials, 6: 444-479.

Lasko, K., Vadrevu, K., 2018. Improved rice residue burning emissions estimates: Accounting for practice-specific emission factors in air pollution assessments of Vietnam. Environmental Pollution, 236: 795-806.

Liu, Y., Chang, C.-W., Namdar, A., She, Y., Lin, C.-H., Yuan, X., Yang, Q., 2019a. Stabilization of expansive soil using cementing material from rice husk ash and calcium carbide residue. Construction and Building Materials, 221:1-11.

Liu, Y., Su, Y., Namdar, A., Zhou, G., She, Y., Yang, Q., 2019b. Utilization of cementitious material from residual rice husk ash and lime in stabilization of expansive soil. Advances in Civil Engineering 2019.

Miura, N., Horpibulsuk, S., Nagaraj, T.S., 2001. Engineering behavior of cement stabilized clay at high water content. Soils and Foundations, 41: 33-45.

Nguyen, N., Ye, G., Van Breugel, K., Fraaij, A.L., Dai Bui, D., 2011. The study of using rice husk ash to produce ultra high performance concrete. Construction and Building Materials, 25: 2030-2035.

Okafor, F.O., Okonkwo, U.N., 2009. Effects of rice husk ash on some geotechnical properties of lateritic soil. Nigerian Journal of Technology, 28: 46-52.

Rahman, M. A., 1987. Effects of cement-rice husk ash mixtures on geotechnical properties of lateritic soils. Soils and Foundations, 27: 61-65.

Roy, A., 2014. Soil stabilization using rice husk ash and cement. International journal of civil engineering research, 5: 49-54.

Sarkar, G., Islam, M. R., Alamgir, M., Rokonuzzaman, M., 2012. Interpretation of rice husk ash on geotechnical properties of cohesive soil. Global Journal of Research In Engineering 12.

Sekhar, D. C., Nayak, S., Preetham, H. K., 2017. Influence of granulated blast furnace slag and cement on the strength properties of lithomargic clay. Indian Geotechnical Journal, 47: 384-392.

Sharma, A. K., Sivapullaiah, P.V., 2016. Ground granulated blast furnace slag amended fly ash as an expansive soil stabilizer. Soils and Foundations, 56: 205-212.

Thao, P.T. M., Kurisu, K. H., Hanaki, K., 2011. Greenhouse gas emission mitigation potential of rice husks for An Giang province, Vietnam. Biomass and Bioenergy, 35: 3656-3666.

Thi Nu' N., Duong, N. T., Son, B. T., and Thinh, P. H., 2020. Investigation of salt, alum content in soft soils and their effects on soil properties: case study in coastal areas of Vietnam, Iraqi Geological Journal, 53 (2A): 19-34.

Varaprasad, B. J. S., Reddy, J. J., Reddy, J. S., 2020. Remediation of expansive soils using mango kernel ash and calcium carbide residue. IJEWM 25, 220. https://doi.org/10.1504/JJEWM.2020.105351

Yoobanpot, N., Jamsawang, P., 2014. Effect of cement replacement by rice husk ash on soft soil stabilization. Kasetsart Journal-Natural Science, 48: 323-332. 